Tạp chí Khoa học và Công nghệ biển T11 (2011). Số 4. Tr 75 - 96

\title{
MÔ HÌNH CHU TRÌNH CHUYỂN HOÁ NITƠ TRONG HỆ SINH THÁI BIỂN ÁP DỤNG CHO VÙNG BIỂN VỊNH BẮC Bộ
}

\author{
NGUYẼ̃N NGỌC TIẾN \\ Viện Địa chất và Địa vật lý biển
}

NGUYẼ̃N CHÍ CÔNG

Viện Hải dương học

DƯ VĂN TOÁN

Tổng cục Biển và Hải đảo Việt Nam

\begin{abstract}
Tóm tắt. Bài báo giới thiệu mô hình chu trình chuyển hoá Nitơ trong hệ sinh thái biển và một số kết quả áp dụng mô hình để tính toán năng suất sinh học sơ cấp tại vùng biển vịnh Bắc bộ. Bài giới thiệu chu trình, nguyên tố Nito được chuyển hoá qua 5 hợp phần: thục vật nổi, động vật nổi, chất hũu co hoà tan, Amoni và Nitrat. Các quá trình chuyển hoá trong chu trình được mô phỏng toán học bằng hệ phương trình vi phân hũu tuyến. Kết quả tính toán cho thấy sức sản xuất so cấp thô của vùng biển vịnh Bắc bộ trong mùa đông dao động chủ yếu tù $30-63 \mathrm{mgC} / \mathrm{m}^{3} /$ ngày, trung bình $57 \mathrm{mgC/m} /$ ngày, trong đó luợng sản phẩm tinh dao động tù

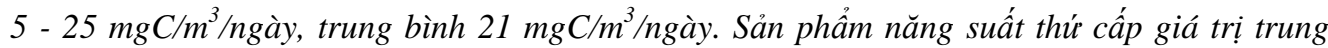
bình $5,6 \mathrm{mgC} / \mathrm{m}^{3} / \mathrm{ngày} \mathrm{và} \mathrm{dao} \mathrm{động} \mathrm{trong} \mathrm{khoảng} 2,8-6,0 \mathrm{mgC} / \mathrm{m}^{3} / \mathrm{ngày}$. Hệ số P/B ngày của thực vật nổi có giá trị trung bình 0,85 , hiệu suất tụ duỡng 1,54 và hiệu suất chuyển hoá năng lượng tư nhiên của vùng biển khoảng 0,03\%. Trong mùa hè, sức sản xuất so cấp thô dao động trong khoảng $67-77 \mathrm{mgC} / \mathrm{m}^{3} /$ ngày, trung bình $72,43 \mathrm{mgC} / \mathrm{m}^{3} /$ ngày, luọng sản phẩm tinh dao động trong khoảnng $28-32 \mathrm{mgCl} \mathrm{m}^{3} /$ ngày trung bình $30 \mathrm{mgC} / \mathrm{m}^{3} / n g a ̀ y$, năng suất thứ cấp dao động trong khoảng $6.0-6.6 \mathrm{mgC} / \mathrm{m}^{3} / \mathrm{ngày}$, trung bình đạt $6.36 \mathrm{mgC} / \mathrm{m}^{3} / \mathrm{ngày}$. Hệ số P/B ngày của thực vật nổi có giá trị trung bình 1.02, hiệu suất tư duỡng 1,7 và hiệu suất chuyển hoá năng lự̂ng tụ nhiên của vùng biển khoảng 0,02\%.
\end{abstract}

\section{MỎ̉ ĐÀ̀U}

Quan trắc, đo đạc các yếu tố hóa sinh tại các vùng biển Việt Nam còn chưa được thực hiện thường xuyên và có hệ thống. Trong công trình này, các tác giả đã sử dụng các mô hình toán và phương pháp số trong nghiên cứu hệ sinh thái biển ở Việt Nam. Hướng nghiên cứu này có nhiều triển vọng, được xây dựng trên cơ sở mô phỏng toán học chu 
trình chuyển hoá vật chất trong hệ sinh thái biển nhằm xác định được những quy luật cơ bản, phổ biến và dự báo biến động của các hợp phần vô sinh, hữu sinh, đặc biệt trong việc kiểm soát môi trường và hệ sinh thái biển.

Trong bài viết này, chúng tôi giới thiệu mô hình chu trình Nitơ cùng những mô phỏng toán học các quá trình chuyển hoá trong chu trình và một số kết quả áp dụng tại vùng biển vịnh Bắc bộ trong 12 tháng nhằm phân tích sự phân bố trong mùa đông và mùa hè.

\section{PHƯƠNG PHÁP NGHIÊN CỨU}

\section{Sơ đồ chu trình chuyển hóa Nitơ trong hệ sinh thái biển}

Mô hình chu trình chuyển hoá Nitơ trong hệ sinh thái biển được biểu diễn trên sơ đồ hình 1. Trong chu trình, nguyên tố Nitơ được chuyển hoá qua 5 hợp phần: thực vật nổi (Phytoplankton- sinh khối được ký hiệu là PHY), động vật nổi (Zooplankton - ZOO), chất hữu cơ hoà tan (Dissolved Organic Matter - DOM), Amoni (Amonium - AMO), Nitrat (Nitrate - NIT). Trong nghiên cứu này, sinh khối hoặc hàm lượng của các hợp phần được tính theo khối lượng Nitơ có trong hợp phần đó và được biểu diễn bằng số micro-nguyên tử gam Nitơ có trong 1 lít nước biển $(\mu \mathrm{AT}-\mathrm{gN} / \mathrm{l})$. Có thể quy đổi đơn vị đo này thành các đơn vị đo thường hay sử dụng trong nghiên cứu sinh học biển theo tỷ lệ là $0,660 \mathrm{mg}$ lượng chất tươi sinh vật phù du biển có chứa $1 \mu \mathrm{AT}$-gN [6]. Các quá trình chuyển hoá trong chu trình được diễn tả như sau:

\section{Quá trình chuyển hoá 1: Quang hợp của Phytoplankton.}

Trong quá trình này dưới tác động của năng lượng ánh sáng mặt trời, Phytoplankton đã sử dụng khí $\mathrm{CO}_{2}$, nước và các muối dinh dưỡng trong đó có Amoni (đường dẫn 1a), Nitrit (1b) và Nitrat (1c) của môi trường để tổng hợp chất hữu cơ. Quá trình này đã chuyển hoá Nitơ vô cơ từ môi trường thành Nitơ liên kết trong tế bào tảo (làm giảm $\mathrm{AMO}, \mathrm{NRIT}$ và NRAT và làm tăng PHY). Khối lượng gia tăng của quần thể Phytoplankton trong một đơn vị thời gian thực hiện quang hợp (thường tính trong 1 ngày) chính là năng suất sinh học sơ cấp thô (Rough primary productivity), một tham số quan trọng để đánh giá tiềm năng sinh học của vùng biển. Cường độ quá trình này phụ thuộc vào sinh khối quần thể Phytoplankton, nồng độ các muối dinh dưỡng Amoni, Nitrit, Nitrat, nhiệt độ môi trường và năng lượng bức xạ quang hợp (Photosynthetically Active Radiation - PAR) [4, 5, 6, 7].

\section{Quá trình chuyển hoá 2: Hô hấp của Phytoplankton}

Trong quá trình này, một phần lượng chất hữu cơ được thành tạo trong quang hợp bị ôxy hoá làm giảm sinh khối PHY, kèm theo đó là sự giải phóng một số hợp phần vô cơ 
trong đó có các hợp chất Nitơ vô cơ, làm tăng nồng độ AMO (đường dẫn 2a) và NIT (2b). Hiệu số giữa lượng chất hữu cơ được thành tạo trong quang hợp và lượng chất hữu cơ bị mất đi trong quá trình hô hấp của Phytoplankton trong 1 đơn vị thời gian (thường tính trong 1 ngày) chính là năng suất sơ cấp tinh (Pure primary productivity). Đó cũng chính là phần vật chất (năng lượng) còn lại được tích luỹ trong sản phẩm của Phytoplankton để các bậc dinh dưỡng kế tiếp, trước hết là Zooplankton sử dụng theo các kênh dinh dưỡng trong hệ sinh thái vùng biển.

\section{Quá trình chuyển hoá 3: Dinh dương của Zooplankton}

Trong quá trình này Zooplankton sử dụng Phytoplankton làm thức ăn để tồn tại và phát triển. Cường độ sử dụng thức ăn của Zooplankton phụ thuộc vào hàm lượng thức ăn (PHY), sinh khối và bản chất quần thể Zooplankton. Quá trình chuyển hoá này làm giảm sinh khối quần thể Phytoplankton, trong đó phần thức ăn thực sự được sử dụng vào đồng hoá (đường dẫn $3 \mathrm{a}$ ) sẽ làm tăng sinh khối quần thể Zooplankton, phần không sử dụng (3b) sẽ trở lại môi trường và làm tăng sinh khối chất hữu cơ (DOM).

\section{Quá trình chuyển hoá 4: Hô hấp của Zooplankton}

Hô hấp của Zooplankton là quá trình ngược lại với đồng hoá của nó. Trong quá trình này phần vật chất (năng lượng) đã lấy được do đồng hoá thức ăn lại bị ôxy hoá để giải phóng năng lượng và Zooplankton sử dụng năng lượng này để tồn tại và phát triển. Cơ chế hô hấp của Zooplankton được thể hiện đơn giản qua phản ứng sau:

$$
\mathrm{C}_{\mathrm{n}} \mathrm{H}_{2 \mathrm{n}} \mathrm{O}_{\mathrm{n}}+\mathrm{nO}_{2}=\mathrm{nCO}_{2}+\mathrm{nH}_{2} \mathrm{O}+\mathrm{Q}
$$

Kèm theo năng lượng được giải phóng là các sản phẩm vật chất được thải ra môi trường dưới dạng các sản phẩm bài tiết, trong đó có Amoni.

Như vậy, hô hấp của Zooplankton đã làm giảm sinh khối ZOO và tăng nồng độ AMO. Cường độ quá trình này phụ thuộc chủ yếu vào nhiệt độ môi trường. Hiệu số giữa lượng sản phẩm đồng hoá và lượng sản phẩm tiêu huỷ do hô hấp của Zooplankton trong một đơn vị thời gian (thường tính trong 1 ngày) chính là năng suất thứ cấp của bậc dị dưỡng thứ nhất. Đây là phần vật chất (năng lượng) còn lại được tích luỹ trong sản phẩm của Zooplankton để các bậc dinh dưỡng kế tiếp (các động vật bậc cao) sử dụng theo các kênh dinh dưỡng trong hệ sinh thái vùng biển.

Quá trình chuyển hoá 5 và 6: Chết tự nhiên của quần thể Phytoplankton và Zooplankton

Quá trình này làm giảm sinh khối các quần thể và làm tăng sinh khối chất hữu cơ (DOM). Đối với PHY, cường độ quá trình chết tự nhiên bị giới hạn bởi nồng độ các muối dinh dưỡng (AMO và $\mathrm{NIT})$, đối với $\mathrm{ZOO}$ - bị giới hạn bởi hàm lượng thức ăn (PHY). 


\section{Quá trình chuyển hoá 7: Khoáng hoá chất hữu co}

Phân huỷ và khoáng hoá chất hữu cơ trong biển (các xác chết, các sản phẩm dư thừa trong các hoạt động sống) là một tập hợp các quá trình lý-hoá-sinh học rất phức tạp, có sự tham gia của các sinh vật (chủ yếu là vi sinh vật phân giải) và các chất như Ôxy, nước,...Trong quá trình phân huỷ, năng lượng còn lại trong chất hữu cơ được giải phóng và các sinh vật phân giải sử dụng năng lượng này để tồn tại và phát triển. Sản phẩm cuối cùng của quá trình phân huỷ và khoáng hoá chất hữu cơ là các chất vô cơ được hoàn lại cho môi trường. Cường độ quá trình này phụ thuộc bản chất chất hữu cơ, lượng các sinh vật phân giải và nhiều điều kiện phân giải, trong đó quan trọng hơn hết là nhiệt độ môi trường.

Đối với chu trình Nitơ, các sản phẩm vô cơ được giải phóng trong quá trình phân huỷ và khoáng hoà là Amoniac, Amoni, Nitrit, Nitrat. Tuy nhiên, do sự phức tạp của khâu phân huỷ các hợp chất Nitơ hữu cơ trong chu trình mà người ta thường coi sản phẩm vô cơ đầu tiên ở khâu này chỉ là Amôni như đã thấy trên hình 1 . Như vậy, theo sơ đồ này thì quá trình phân huỷ chất hữu cơ làm giảm sinh khối DOM và trực tiếp làm tăng nồng độ của chỉ riêng AMO.

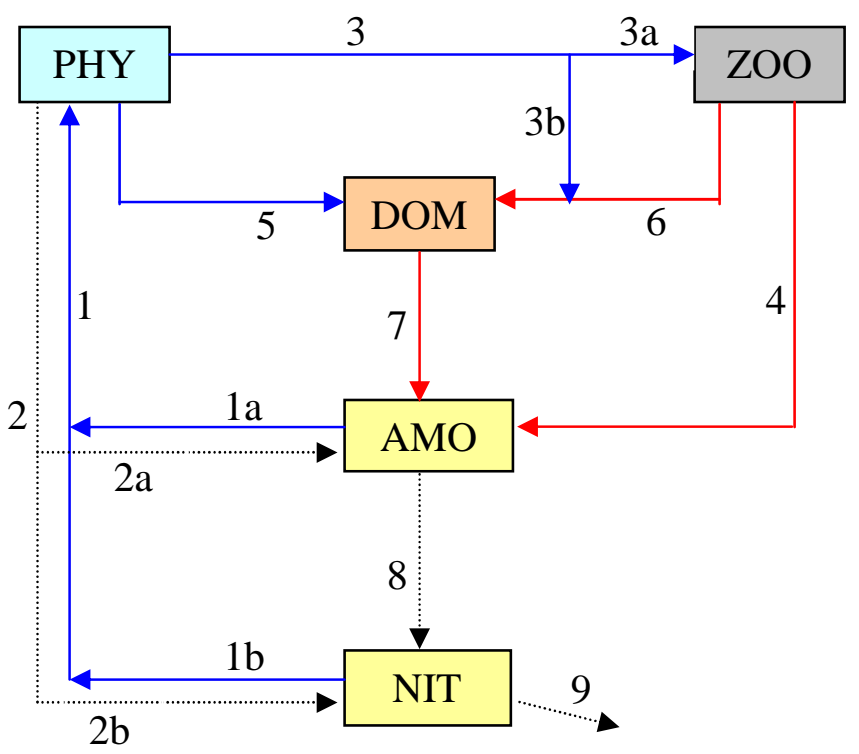

Hình 1: Sơ đồ chu trình chuyến hoá Nitơ trong hệ sinh thái biển. Chú giải: $P H Y$ : Phytoplankton; ZOO: Zooplankton; DOM: Chất hũu co hoà tan; AMO: Amoni; NIT: Nitrat; 1... 9: Các quá trình chuyển hoá; $\longrightarrow:$ Hướng chuyển hoá 
Quá trình chuyển hoá 8 - Đạm hoá (Nitrification) và quá trình chuyển hoá 9 - Phi đạm hoá (Denitrification)

Trong nghiên cứu này, chúng tôi đã bổ sung cho sơ đồ chu trình Nitơ 2 quá trình nêu trên. Đạm hoá là quá trình ôxy hoá chuyển Amoni thành Nitrat, phi đạm hoá là quá trình khử Nitrat thành Nitơ tự do.

Cơ chế quá trình đạm hoá:

$$
\begin{aligned}
& \mathrm{NH}_{4}^{+}+2 \mathrm{O}_{2} \longrightarrow \mathrm{NO}_{3}^{-}+\mathrm{H}_{2} \mathrm{O}+2 \mathrm{H}^{+} \\
& \mathrm{NH}_{3}+2 \mathrm{O}_{2} \longrightarrow \mathrm{NO}_{3}^{-}+\mathrm{H}_{2} \mathrm{O}+\mathrm{H}^{+}
\end{aligned}
$$

Cơ chế quá trình phi đạm hoá:

$$
5 \mathrm{CH}_{2} \mathrm{O}+5 \mathrm{H}_{2} \mathrm{O}+4 \mathrm{NO}_{3}{ }^{-}+4 \mathrm{H}^{+} \longrightarrow 5 \mathrm{CO}_{2}+2 \mathrm{~N}_{2}+12 \mathrm{H}_{2} \mathrm{O}
$$

\section{Mô hình toán chu trình chuyển hóa Nito}

Theo nguyên lý bảo toàn, tốc độ toàn phần biến đổi sinh khối hoặc nồng độ của một hợp phần sinh, hoá học nào đó chính là tổng đại số tốc độ các quá trình sản sinh làm tăng (nguồn-Production) và phân huỷ làm suy giảm (phân huỷ-Destruction) nồng độ hoặc sinh khối của hợp phần đó. Gọi $\mathrm{C}^{\mathrm{i}}$ là nồng độ (hoặc sinh khối) của hợp phần i, Prod ${ }^{\mathrm{i}}$, Dest $\mathrm{i}^{\mathrm{i}}$ tương ứng là tốc độ các quá trình làm tăng và làm giảm nồng độ (hoặc sinh khối) của hợp phần, ta có:

$$
\frac{\mathrm{dC}^{\mathrm{i}}}{\mathrm{dt}}=\operatorname{Pr} o d^{i}-\text { Dest }^{i}
$$

Ở đây $\mathrm{i}=1 . . .5$ tương ứng là PHY, ZOO, DOM, AMO, NIT.

Từng hợp phần của chu trình Nitơ, các biểu thức mô phỏng $\operatorname{Prod}^{\mathrm{i}}$, Dest ${ }^{\mathrm{i}}$ như sau $[6,7]$ :

$$
\begin{aligned}
& \operatorname{Prod}^{P H Y}=L(i) \cdot L^{*}(\xi)\left[\frac{\delta_{A}^{P} \cdot A M O}{C_{A}+A M O}+\frac{\delta_{N}^{P} N I T}{C_{N}+N I T} \operatorname{Exp}(-\lambda . A M O] \cdot P H Y\right. \\
& \operatorname{Dest}^{P H Y}=F_{P}^{N} \cdot P H Y+\frac{\delta_{P}^{Z} \cdot P H Y}{C_{P}+P H Y} Z O O+F_{P}^{D} \cdot P H Y \\
& \operatorname{Prod}{ }^{\text {ZOO }}=\left(1-X_{P}\right) \frac{\delta_{P}^{Z} P H Y}{C_{P}+P H Y} Z O O \\
& \operatorname{Dest}^{\text {ZOO }}=\left(F_{Z}^{A}+F_{Z}^{D}\right) Z O O
\end{aligned}
$$




$$
\begin{aligned}
& \operatorname{Prod}{ }^{D O M}=\frac{X_{P} \delta_{P}^{Z} P H Y \cdot Z O O}{C_{P}+P H Y}+F_{P}^{D} \cdot P H Y+F_{Z}^{D} \cdot Z O O \\
& \operatorname{Dest}^{D O M}=F_{D}^{A} \cdot D O M \\
& \operatorname{Prod}^{A M O}=F_{Z}^{A} Z O O+F_{D}^{A} D O M+\alpha_{A M O} F_{P}^{N} P H Y \\
& \operatorname{Dest}^{A M O}=L(i) \cdot L(\xi) \frac{\delta_{A}^{P} A M O}{C_{A}+A M O} P H Y+F_{A}^{N} A M O \\
& \operatorname{Prod} d^{N I T}=F_{A}^{N} A M O+\alpha_{N I T} F_{P}^{N} P H Y \\
& \operatorname{Dest}^{N I T}=L(i) L(\xi) \frac{\delta_{N}^{P} \cdot N I T}{C_{N}+N I T} \operatorname{Exp}(-\lambda \cdot A M O) \cdot P H Y+F_{N}^{O} N I T
\end{aligned}
$$

Trong các mô phỏng toán học kể trên, $L(i), L^{*}(\xi)$ là ảnh hưởng của nhiệt độ và cường độ chiếu sáng, $F_{P}^{N}, F_{P}^{D}, F_{Z}^{A}, F_{Z}^{D}, F_{D}^{A}, F_{Z}^{A}, F_{A}^{N}, F_{N}^{O}$ là tốc độ riêng của các quá trình chuyển hoá (các đại lượng này được tính toán theo các công thức thực nghiệm [6, 7]. Các ký hiệu còn lại là các thông số (hằng số) của mô hình, ý nghĩa và giá trị của chúng đối với vùng biển vịnh Bắc bộ được cho ở bảng 1 .

\section{Phương trình cơ bản của mô hình}

Mô hình toán chu trình chuyển hoá Nitơ được viết lại ở dạng tổng quát sau:

$$
\frac{d C^{i}}{d t}=\operatorname{Pr} o d^{i}-D e s t^{i}
$$

Với $i=1 \ldots 5$ tương ứng là 5 hợp phần của chu trình Nitơ. Đây là hệ phương trình vi phân thường gồm 5 phương trình, có thể giải bằng nhiều phương pháp, ở đây chọn phương pháp Runger Kuta với điều kiện ban đầu:

$$
\mathrm{C}^{\mathrm{i}}\left(\mathrm{t}=\mathrm{t}_{0}\right)=\mathrm{C}^{\mathrm{i}^{*}} \text { (biết trước) }
$$

Kết quả của mô hình (12) với điều kiện (13) cho ta biến động theo thời gian của sinh khối, hàm lượng các hợp phần, cùng năng suất sinh học sơ cấp, thứ cấp và các hiệu quả sinh thái của vùng biển.

Với mục đích nghiên cứu hiện trạng phân bố các hợp phần trong chu trình Nitơ và các đặc trưng của các quá trình sản xuất vật chất hữu cơ bậc thấp ở vùng biển tại một thời điểm nào đấy, bài toán (12) được giải trong điều kiện dừng $\left(\mathrm{dC}^{\mathrm{i}} / \mathrm{dt}=0, \mathrm{i}=1 \ldots 5\right)$ nghĩa là: 
Phương pháp lặp Runge - Kuta vẫn được áp dụng cho bài toán dừng, song cần phải kiểm tra tính hội tụ. Cụ thể, với các điều kiện môi trường không đổi trong suốt quá trình lặp, nếu tại bước tính thứ $\mathrm{n}$ đủ lớn mà nghiệm tính được chỉ sai khác với nghiệm ở bước thứ n-1 một giá trị $\varepsilon$ nhỏ bé cho trước thì xem như quá trình đã đạt đến tựa dừng. Với cách xử lý này, nghiệm ban đầu (13) có thể cho trước tuỳ ý $\neq 0$. Ngoài ra khi xem xét toàn bộ các thông số của mô hình thấy rằng: Để giải được bài toán này còn cần phải có các thông số sinh thái và các số liệu đo về nhiệt độ, cường độ chiếu sáng tại thời điểm nào đó (khảo sát) tại vùng biển. Toàn bộ giá trị các tham số trên là không đổi trong suốt quá trình lặp đến nghiệm tựa dừng.

Bảng 1: Các thông số (hằng số) sử dụng trong mô hình và giá trị lựa chọn cho vùng biển vịnh Bắc bộ

\begin{tabular}{|c|c|c|c|c|}
\hline TT & Ký hiệu & Thông số & Thứ nguyên & Giá trị \\
\hline 1 & $\delta_{N}^{P}$ & Tốc độ riêng cực đại sử dụng Nitrat trong quang hợp & $(\text { Ngày })^{-1}$ & 2.2 \\
\hline 2 & $\delta_{A}^{P}$ & Tốc độ riêng cực đại sử dụng Amoni trong quang hợp & $(\text { Ngày })^{-1}$ & 1.8 \\
\hline 3 & $\mathrm{C}_{\mathrm{N}}$ & Hệ số bán bão hoà muối Nitrat & $\mu \mathrm{AT}-\mathrm{gN} / 1$ & 0.15 \\
\hline 4 & $\mathrm{C}_{\mathrm{A}}$ & Hệ số bán bão hoà muối Amoni & $\mu \mathrm{AT}-\mathrm{gN} / 1$ & 0.3 \\
\hline 5 & $P A R_{O P T}$ & Cường độ sáng thích hợp cho quang hợp & $\mathrm{W} / \mathrm{m}^{2}$ & 120 \\
\hline 6 & $\beta_{\mathrm{T}}$ & Hệ số biểu thị ức chế quang hợp do nhiệt độ & - & -0.5 \\
\hline 7 & $\beta_{\text {I }}$ & Hệ số biểu thị ức chế quang hợp do ánh sáng & - & -0.5 \\
\hline 8 & $\mathrm{~T}_{\text {Leth }}$ & Cận dưới nhiệt độ quang hợp & ${ }^{\circ} \mathrm{C}$ & 15 \\
\hline 9 & $\mathrm{~T}_{\mathrm{OPT}}$ & Nhiệt độ tối thuận cho quang hợp & ${ }^{\circ} \mathrm{C}$ & 27 \\
\hline 10 & $\lambda$ & $\begin{array}{c}\text { Hệ số biểu thị sự ức chế tác dụng của NIT trong quang } \\
\text { hợp khi có } \mathrm{AMO}\end{array}$ & $\begin{array}{l}(\mu \mathrm{AT}- \\
\mathrm{gN} / 1)^{-1}\end{array}$ & 1.5 \\
\hline 11 & $\delta_{M}^{P}$ & Tốc độ riêng chết cực đại của PHY & $\left(\right.$ Ngày $^{-1}$ & 0.9 \\
\hline 12 & $\delta_{m}^{P}$ & Tốc độ riêng chết cực tiểu của PHY & $(\text { Ngày })^{-1}$ & 0.3 \\
\hline 13 & $\mathrm{P}_{0}$ & $\begin{array}{l}\text { Hệ số thực nghiệm (xác định cường độ hô hấp của } \\
\text { PHY) }\end{array}$ & - & 0.05 \\
\hline 14 & $\mathrm{Q}_{0}$ & $\begin{array}{l}\text { Hệ số thực nghiệm (xác định cường độ hô hấp của } \\
\text { PHY) }\end{array}$ & - & 0.01 \\
\hline
\end{tabular}




\begin{tabular}{|c|c|c|c|c|}
\hline 15 & $\mathrm{U}_{0}$ & $\begin{array}{l}\text { Hệ số thực nghiệm (xác định cường độ hô hấp của } \\
\text { PHY) }\end{array}$ & - & 0.187 \\
\hline 16 & $\mathrm{M}_{\mathrm{P}}$ & Kích thước trung bình tế bào tảo & $\mu \mathrm{m}$ & $3.10^{-6}$ \\
\hline 17 & $\mathrm{~T}_{\mathrm{HH}}$ & Nhiệt độ thuận cho quá trình hô hấp của PHY & ${ }^{\circ} \mathrm{C}$ & 20 \\
\hline 18 & $\mathrm{~N}_{\mathrm{m}}$ & $\begin{array}{c}\text { Giá trị ngưỡng Nitơ tổng (AMO+NIT) tại đó cường độ } \\
\text { chết của PHY đạt cực đại }\end{array}$ & $\mu \mathrm{AT}-\mathrm{gN} / 1$ & 0.3 \\
\hline 19 & $\alpha_{\mathrm{N}}$ & Tỷ lệ Nitơ vô cơ trong sản phẩm hô hấp của PHY & - & 0.16 \\
\hline 20 & $\alpha_{\text {АMO }}$ & $\begin{array}{l}\text { Tỷ lệ của Amoni trong phần Nitơ vô cơ của sản phẩm } \\
\text { hô hấp của Phytoplankton }\end{array}$ & - & 0.4 \\
\hline 21 & $\alpha_{\mathrm{NIT}}$ & $\begin{array}{l}\text { Tỷ lệ Nitrat trong phần Nitơ vô cơ của sản phẩm hô } \\
\text { hấp của Phytoplankton }\end{array}$ & - & 0.4 \\
\hline 22 & $\delta_{P}^{Z}$ & Tốc độ riêng cực đại sử dụng PHY (bắt mồi) của ZOO & $(\text { Ngày })^{-1}$ & 1.5 \\
\hline 23 & $\delta_{M}^{Z}$ & Tốc độ riêng chết cực đại của ZOO & $(\text { Ngày })^{-1}$ & 0.8 \\
\hline 24 & $\delta_{m}^{Z}$ & Tốc độ riêng chết cực tiểu của $\mathrm{ZOO}$ & $(\text { Ngày })^{-1}$ & 0.05 \\
\hline 25 & $\mathrm{C}_{\mathrm{P}}$ & Hệ số bán bão hoà hàm lượng thức ăn & $\mu \mathrm{AT}-\mathrm{gN} / 1$ & 0.5 \\
\hline 26 & $\mathrm{X}_{\mathrm{P}}$ & Tỷ lệ của phần thức ăn không đồng hoá & - & 0.4 \\
\hline 27 & $\mathrm{PHY}_{\mathrm{m}}$ & $\begin{array}{l}\text { Giá trị ngưỡng của lượng thức ăn PHY tại đó cường độ } \\
\text { chêt của } \mathrm{ZOO} \text { cực đại }\end{array}$ & $\mu \mathrm{AT}-\mathrm{gN} / 1$ & 1.0 \\
\hline 28 & $\delta_{Z}^{A}$ & Tốc độ riêng bài tiết Amoni tại $0^{\circ} \mathrm{C}$ & $(\text { Ngày })^{-1}$ & 0.1 \\
\hline 29 & $\mathrm{~b}_{\mathrm{e}}$ & Hệ số biểu thị ảnh hưởng nhiệt độ đến tốc độ bài tiết & - & 1.03 \\
\hline 30 & $\delta_{D}^{A}$ & Tốc độ riêng phân huỷ thành Amoni tại $20^{\circ} \mathrm{C}$ & $(\text { Ngày })^{-1}$ & 0.7 \\
\hline 31 & $\mathrm{~K}_{\mathrm{T}}$ & Hệ số biểu thị ảnh hưởng của nhiệt độ đến $\delta_{D}^{A}$ & - & 1.05 \\
\hline 32 & $\mathrm{~K}_{\mathrm{AMO}}$ & Tốc độ riêng đạm hoá chuyển Amoni thành Nitrat & - & 0.087 \\
\hline 33 & $\mathrm{~K}_{\mathrm{NIT}}$ & Tốc độ riêng phi đạm hoá chuyển Amoni thành Nitrat & - & 0.00001 \\
\hline 34 & $\mathrm{I}_{0}$ & Hằng số mặt trời & $\mathrm{W} / \mathrm{m}^{2}$ & 1353 \\
\hline 35 & $\mathrm{C}_{1}$ & Hệ số thực nghiệm & - & 0.56 \\
\hline 36 & $\mathrm{C}_{2}$ & Hệ số thực nghiệm & - & 0.16 \\
\hline 37 & $\Delta_{\mathrm{T}}$ & Bước tính & Ngày & 0.01 \\
\hline 38 & $\varepsilon$ & Tham số điều khiển chế độ dừng & - & $10^{-6}$ \\
\hline
\end{tabular}


Trong bài viết này, chúng tôi đã sử dụng và khai thác chương trình NITCYCLE. Đây là một phần mềm mở viết bằng ngôn ngữ Pascal để giải bài toán dừng (12) bằng phương pháp Runge - Kuta áp dụng tại một điểm khảo sát có các tầng khác nhau. Chúng tôi đã viết lại chương trình bằng ngôn ngữ Fortran cho 257 điểm trên toàn vùng nghiên cứu.

\section{KỄT QUẢ ÁP DỤNG MÔ HİNH TẠI VÙNG BIỂN VỊNH BÁ́C Bộ}

Trong bảng 2 và các hình $2,3,4,5,6,7,8,9$ đưa ra một số kết quả cơ bản áp dụng mô hình tại vùng biển vịnh Bắc bộ trong 12 tháng, trong bài viết này chỉ đưa vào tháng 1 đại diện cho mùa đông và tháng 7 đại diện cho mùa hè.

\section{Mùa đông}

Trong tháng 1 , khu vực phát triển của thực vật nổi vịnh Bắc bộ chủ yếu là ở vùng nước ấm trung tâm và cửa vịnh, nơi có nhiệt độ trên $24^{\circ} \mathrm{C}$. Sinh khối của thực vật nổi ở khu vực này đạt khoảng 1110 - 1120 mg-tươi/m³ trung bình 1103 mg-tươi/m³ (hình 2). Vùng nước lạnh ven bờ phía Bắc và Tây Bắc vịnh có nhiệt độ trong khoảng $15,5-21^{\circ} \mathrm{C}$ không thuận lợi cho quang hợp, tại đây sinh khối chỉ đạt cỡ 1065 - 1090 mg tươi $/ \mathrm{m}^{3}$.

So với các thời kỳ khác trong năm thì mùa đông không phải là thời kỳ phát triển của thực vật nổi do nhiệt độ nước giảm thấp, cường độ bức xạ không lớn, lượng dinh dưỡng do các sông tải ra vịnh cũng không nhiều. Đặc biệt, sự giảm thấp của nhiệt độ nước với dải nhiệt tương đối rộng $\left(19-23^{\circ} \mathrm{C}\right)$ là một nhân tố bất lợi cho sự phát triển của thực vật nổi. Đây là thời kỳ có sinh khối thực vật nổi thấp nhất trong năm.

Sức sản xuất sơ cấp thô của vùng biển dao động chủ yếu trong khoảng 30 đến 63 $\mathrm{mgC} / \mathrm{m}^{3} /$ ngày, trung bình $57 \mathrm{mgC} / \mathrm{m}^{3} /$ ngày trong đó lượng sản phẩm tinh dao động trong khoãng 5 đến $25 \mathrm{mgC} / \mathrm{m}^{3} /$ ngày trung bình $21 \mathrm{mgC} / \mathrm{m}^{3} /$ ngày. Phân bố sức sản xuất sơ cấp ở vùng biển có đặc điểm là khu vực phía Nam (sản phẩm thô) cao hơn hẳn khu vực phía Bắc (hình 4), trong đó khu vực ngoài cửa vịnh đạt giá trị cao nhất trên $63 \mathrm{mgC} / \mathrm{m}^{3} / \mathrm{ngày}$ đối với sản phẩm thô và trên $25 \mathrm{mgC} / \mathrm{m}^{3} /$ ngày đối với sản phẩm tinh.

Đối với sản phẩm thứ cấp (động vật nổi), nét tương đồng giữa bức tranh phân bố sinh khối và năng suất của chúng thể hiện khá rõ (hình 6 ) và rất phù hợp với phân bố của sức sản xuất sơ cấp của thực vật nổi, nhất là đối với sản phẩm tinh. Đây là sự biểu hiện rõ nhất và đúng quy luật về quan hệ dinh dưỡng bậc thấp ở vùng biển nghiên cứu. Trong đó sinh khối Động vật nổi (hình 10) đạt giá trị trong khoảng 134 - $329 \mathrm{mg}$-tươi $/ \mathrm{m}^{3}$, giá trị trung bình 288 $\mathrm{mg}$-tươi $/ \mathrm{m}^{3}$, sản phẩm năng suất thứ cấp (hình 8 ) giá trị trung bình $5.6 \mathrm{mgC} / \mathrm{m}^{3} /$ ngày và biến đổi trong khoảng $2,8-6,0 \mathrm{mgC} / \mathrm{m}^{3} /$ ngày. 
Về các hiệu suất sinh thái trong các tháng mùa đông được thể hiện trong bảng 1 và 2 : Hệ số $\mathrm{P} / \mathrm{B}$ ngày của thực vật nổi có giá trị trung bình 0,85 , chứng tỏ tốc độ tổng hợp chất hữu cơ của một đơn vị sinh khối thực vật nổi không lớn. Hệ số P/B ngày của động vật nổi có giá trị trung bình 0.33 . Điều này cũng cho thấy các yếu tố sinh thái của vùng biển trong các tháng mùa đông không ở pha thuận, trong đó vai trò của nhiệt độ nước thể hiện rõ nhất. Tuy nhiên, hiệu suất tự dưỡng vẫn luôn luôn lớn hơn 1 (giá trị trung bình đạt 1,54 ) cho thấy vùng biển vẫn tích luỹ vật chất hữu cơ sơ khởi. Điều này một lần nữa thể hiện sự hạn chế quá trình hô hấp tiêu hao vật chất do nền nhiệt giảm thấp, hiệu suất chuyển hoá năng lượng tự nhiên không cao, một phần do cường độ bức xạ tự nhiên trong các tháng mùa đông giảm, song phần chủ yếu do quá trình tổng hợp chất hữu cơ của thực vật nổi nhỏ.

\section{Mùa hè}

Trong tháng 7 , được xem là mùa phát triển của thực vật nổi với sinh khối hầu khắp vịnh đạt trong khoảng 1132 - $1197 \mathrm{mg}$-tươi $/ \mathrm{m}^{3}$ (hình 3), giá trị trung bình lớn nhất đặt $1159,77 \mathrm{mg}$-tươi $/ \mathrm{m}^{3}$ trong tháng 9 , đặc biệt vùng ven bờ và cửa sông có sinh khối đạt $1198 \mathrm{mg}$-tươi $/ \mathrm{m}^{3}$. Thời kỳ này nhiệt độ nước tầng mặt tăng cao trên $29^{\circ} \mathrm{C}$ và tương đối đồng nhất, lượng dinh dưỡng bổ sung từ lục địa dồi dào. Đây là một trong những điều kiện sinh thái thuận cho quá trình tổng hợp chất hữu cơ của thực vật nổi khu vực ven bờ Tây vịnh Bắc bộ. Phân bố sức sản xuất sơ cấp, tổng lượng sản phẩm thô (hình 5) do thực vật nổi tổng hợp được trong 1 ngày (lấy trung bình ngày 15 hàng tháng) đạt trung bình 72,34 $\mathrm{mgC} / \mathrm{m}^{3} /$ ngày, dao động trong khoảng $67-77 \mathrm{mgC} / \mathrm{m}^{3} /$ ngày. Sinh khối động vật nổi (hình 7) trung bình $388 \mathrm{mg}$-tươi $/ \mathrm{m}^{3}$ dao động trong khoảng $345-445 \mathrm{mgC} / \mathrm{m}^{3} /$ ngày, năng suất thứ cấp (hình 9) trung bình đạt $6.36 \mathrm{mgC} / \mathrm{m}^{3} /$ ngày dao động trong khoảng 6.0 - 6.6 $\mathrm{mgC} / \mathrm{m}^{3} / \mathrm{ngày}$. Đây là những giá trị đặc trưng cho vùng biển nhiệt đới ven bờ giầu dinh dưỡng và có sức sản xuất sơ cấp cao.

Về các hiệu suất sinh thái trong mùa hè: Hệ số $\mathrm{P} / \mathrm{B}$ ngày của thực vật nổi có giá trị trung bình 1.02 cho thấy tốc độ tổng hợp chất hữu cơ của một đơn vị sinh khối thực vật nổi khá cao; Hệ số $\mathrm{P} / \mathrm{B}$ ngày của động vật nổi có giá trị trung bình 0.22 ; hiệu suất tự dưỡng luôn luôn lớn hơn 1 trung bình 1,7 chứng tỏ vật chất tổng hợp được không những đủ chi dùng cho chính thực vật nổi mà còn được tích luỹ khá nhiều trong sản phẩm tinh để các bậc dinh dưỡng tiếp theo sử dụng. Hiệu suất chuyển hoá năng lượng tự nhiên trung bình $0,02 \%$ là ở mức cao so với một số vùng biển ven bờ Việt Nam. 
Bảng 2: Giá trị trung bình các đặc trưng của quá trình sản xuất vật chất hữu cơ trong vùng biển vịnh Bắc bộ

\begin{tabular}{|c|c|c|c|c|c|c|c|c|c|c|c|c|}
\hline Yếu tố & $\begin{array}{c}\text { Tháng } \\
1\end{array}$ & $\begin{array}{c}\text { Tháng } \\
2\end{array}$ & $\begin{array}{c}\text { Tháng } \\
3\end{array}$ & $\begin{array}{c}\text { Tháng } \\
4\end{array}$ & $\begin{array}{c}\text { Tháng } \\
5\end{array}$ & $\begin{array}{c}\text { Tháng } \\
6\end{array}$ & $\begin{array}{c}\text { Tháng } \\
7\end{array}$ & $\begin{array}{c}\text { Tháng } \\
8\end{array}$ & $\begin{array}{c}\text { Tháng } \\
9\end{array}$ & $\begin{array}{c}\text { Tháng } \\
10\end{array}$ & \begin{tabular}{|c|} 
Tháng \\
11
\end{tabular} & $\begin{array}{c}\text { Tháng } \\
12\end{array}$ \\
\hline \multicolumn{13}{|c|}{ Thực vật nổi } \\
\hline $\begin{array}{c}\text { Sinh khối thực } \\
\text { vật nổi } \\
\text { (mg-tươi/ m³) }\end{array}$ & 1103.4 & 1095.9 & 1094.6 & 1107.1 & 1131.5 & 1149.5 & 1156.5 & 1159.5 & 1159.7 & 1155.4 & 1145.0 & 1125.2 \\
\hline $\begin{array}{l}\text { Năng suất thô } \\
\left(\mathrm{mgC} / \mathrm{m}^{3} / \text { ngày) }\right.\end{array}$ & 57.62 & 54.72 & 55.07 & 62.23 & 69.5 & 72.1 & 72.34 & 72.41 & 73.39 & 73.82 & 71.83 & 66.43 \\
\hline $\begin{array}{c}\text { Hô hấp thực vật } \\
\text { nổi } \\
\left(\mathrm{mgC} / \mathrm{m}^{3} / \text { ngày }\right)\end{array}$ & 36.52 & 36.02 & 35.96 & 36.87 & 38.53 & 39.72 & 40.17 & 40.34 & 40.38 & 40.1 & 39.33 & 37.98 \\
\hline $\begin{array}{l}\text { Năng suất tinh } \\
\left(\mathrm{mgC} / \mathrm{m}^{3} / \text { ngày }\right)\end{array}$ & 21.1 & 18.7 & 19.11 & 25.36 & 30.96 & 32.38 & 32.17 & 32.07 & 33.01 & 33.73 & 32.49 & 28.45 \\
\hline \multicolumn{13}{|c|}{ Động vật nổi } \\
\hline $\begin{array}{c}\text { Sinh khối động } \\
\text { vật nổi (mg- } \\
\left.\text { tươi/ } \mathrm{m}^{3}\right)\end{array}$ & 287.98 & 267.75 & 267.47 & 311.2 & 354.46 & 381.3 & 388.76 & 389.87 & 394.92 & 390.77 & 366.39 & 333.67 \\
\hline $\begin{array}{c}\text { Đồng hoá của } \\
\text { động vật nổi } \\
\left(\mathrm{mgC} / \mathrm{m}^{3} / \text { ngày }\right)\end{array}$ & 11.98 & 11.12 & 11.11 & 12.95 & 14.82 & 16.01 & 16.35 & 16.4 & 16.61 & 16.42 & 15.36 & 13.93 \\
\hline $\begin{array}{c}\text { Hô hấp của } \\
\text { động vật nổi } \\
\left(\mathrm{mgC} / \mathrm{m}^{3} / \text { ngày) }\right.\end{array}$ & 6.38 & 5.83 & 5.83 & 7.02 & 8.54 & 9.61 & 9.99 & 10.08 & 10.18 & 9.92 & 9.01 & 7.79 \\
\hline $\begin{array}{l}\text { Năng suất thứ } \\
\text { cấp } \\
\left(\mathrm{mgC} / \mathrm{m}^{3} / \text { ngày }\right)\end{array}$ & 5.59 & 5.29 & 5.28 & 5.93 & 6.28 & 6.4 & 6.36 & 6.32 & 6.44 & 6.5 & 6.35 & 6.14 \\
\hline \multicolumn{13}{|c|}{ Hiệu quả sinh thái } \\
\hline $\begin{array}{c}\text { Hệ số } \mathrm{P} / \mathrm{B} \text { ngày } \\
\text { của } \mathrm{PHY}\end{array}$ & 0.85 & 0.81 & 0.82 & 0.92 & 1 & 1.03 & 1.02 & 1.01 & 1.03 & 1.05 & 1.03 & 0.97 \\
\hline $\begin{array}{l}\text { Hệ số } \mathrm{P} / \mathrm{B} \text { ngày } \\
\text { của } \mathrm{ZOO}\end{array}$ & 0.33 & 0.33 & 0.33 & 0.32 & 0.3 & 0.28 & 0.28 & 0.28 & 0.28 & 0.28 & 0.29 & 0.31 \\
\hline $\begin{array}{l}\text { Hiệu suất tự } \\
\text { dưỡng }\end{array}$ & 1.54 & 1.48 & 1.49 & 1.65 & 1.77 & 1.79 & 1.77 & 1.76 & 1.79 & 1.82 & 1.8 & 1.72 \\
\hline $\begin{array}{c}\text { Hiệu suất } \\
\text { chuyển hoá } \\
\text { năng lượng tự } \\
\text { nhiên }(\%)\end{array}$ & 0.03 & 0.03 & 0.02 & 0.02 & 0.02 & 0.02 & 0.02 & 0.02 & 0.03 & 0.03 & 0.03 & 0.03 \\
\hline $\begin{array}{c}\text { Chuyển hoá } \\
\text { năng lượng qua } \\
\text { TVN-ĐVN }\end{array}$ & 0.39 & 0.39 & 0.4 & 0.25 & 0.21 & 0.21 & 0.21 & 0.21 & 0.2 & 0.2 & 0.2 & 0.22 \\
\hline
\end{tabular}




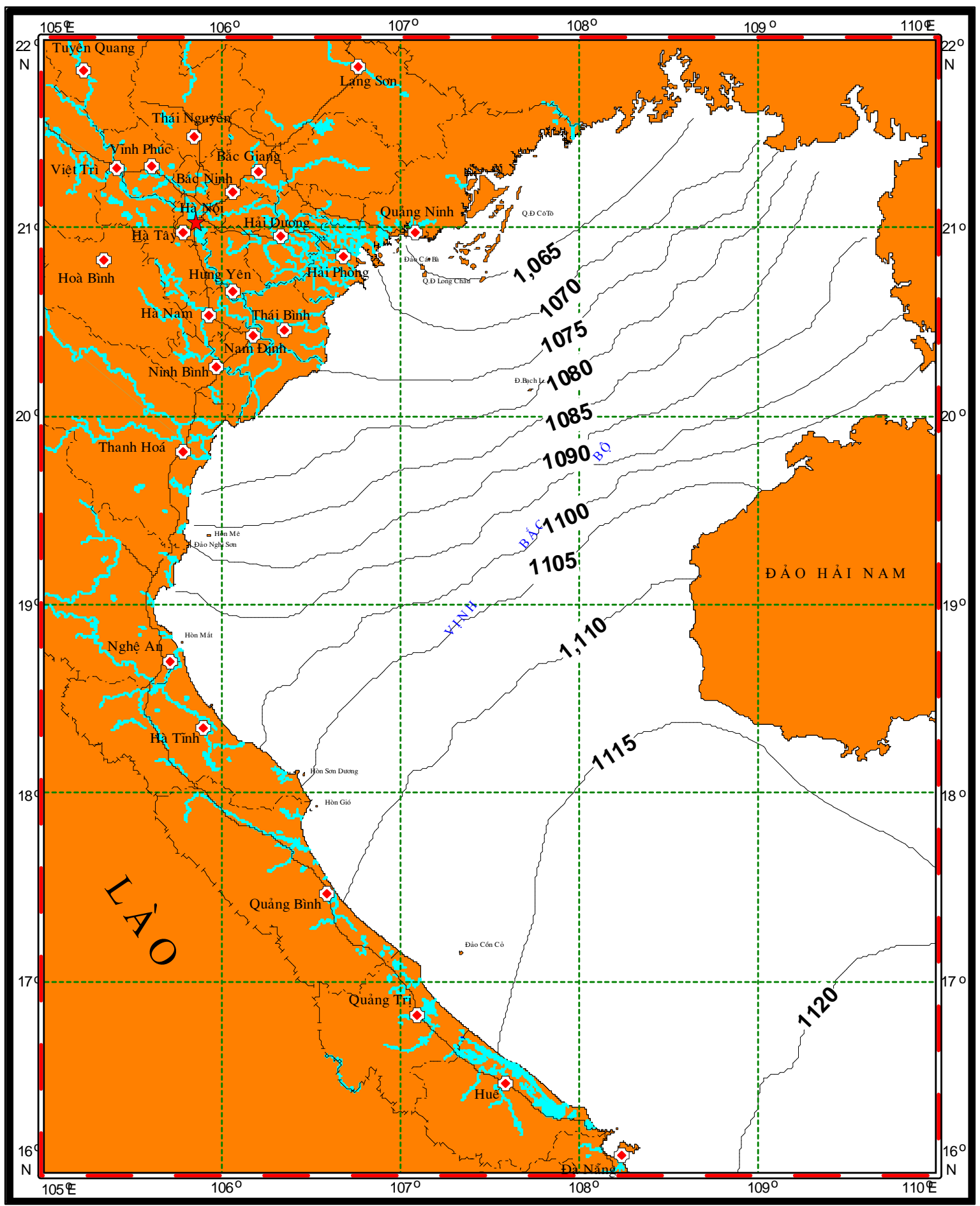

Hình 2: Giá trị trung bình sinh khối thực vật nổi $\left(\mathrm{mg}\right.$-tươi $\left./ \mathrm{m}^{3}\right)$ tháng 1 


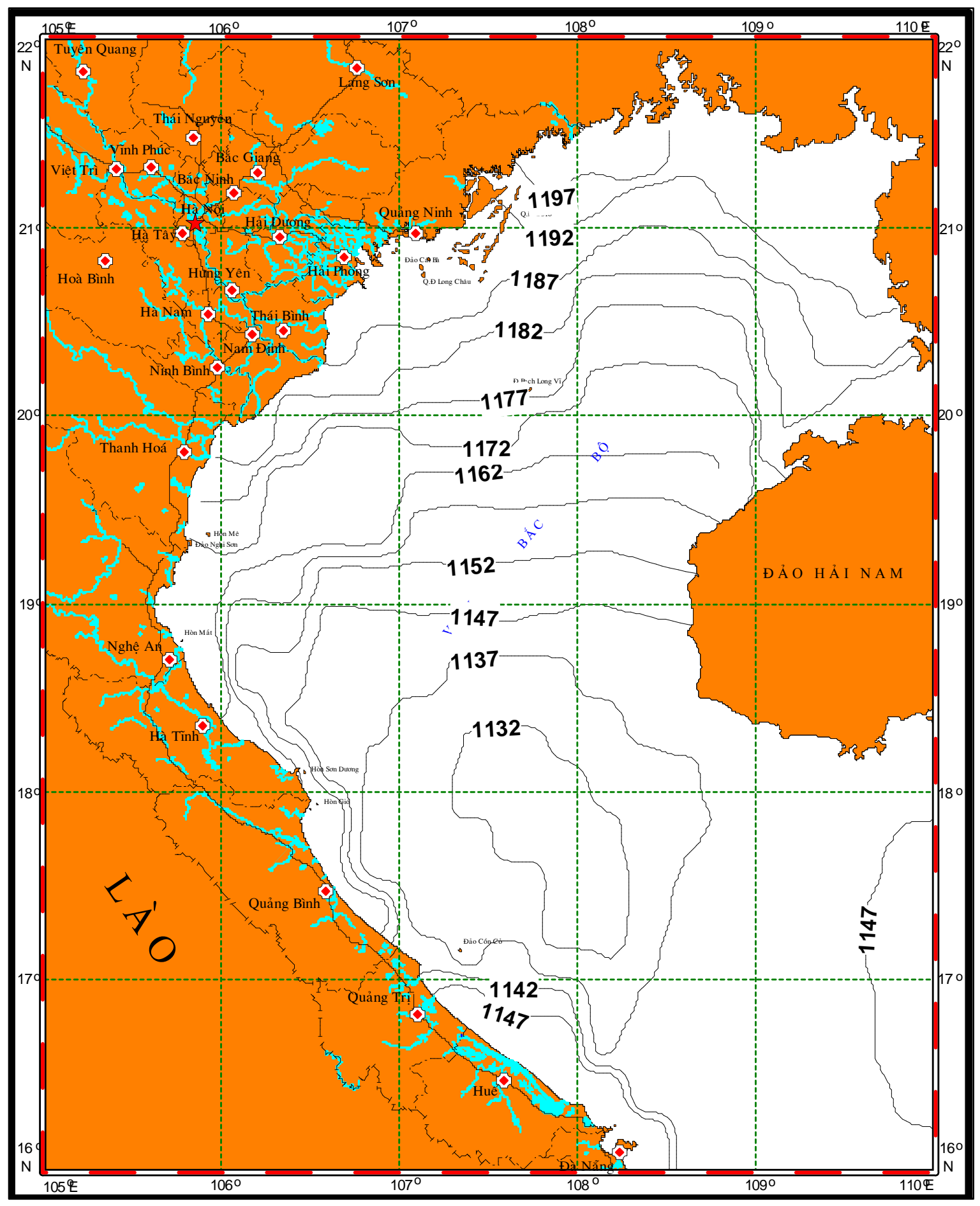

Hình 3: Giá trị trung bình sinh khối thực vật nổi $\left(\mathrm{mg}\right.$-tươi $\left./ \mathrm{m}^{3}\right)$ tháng 7 


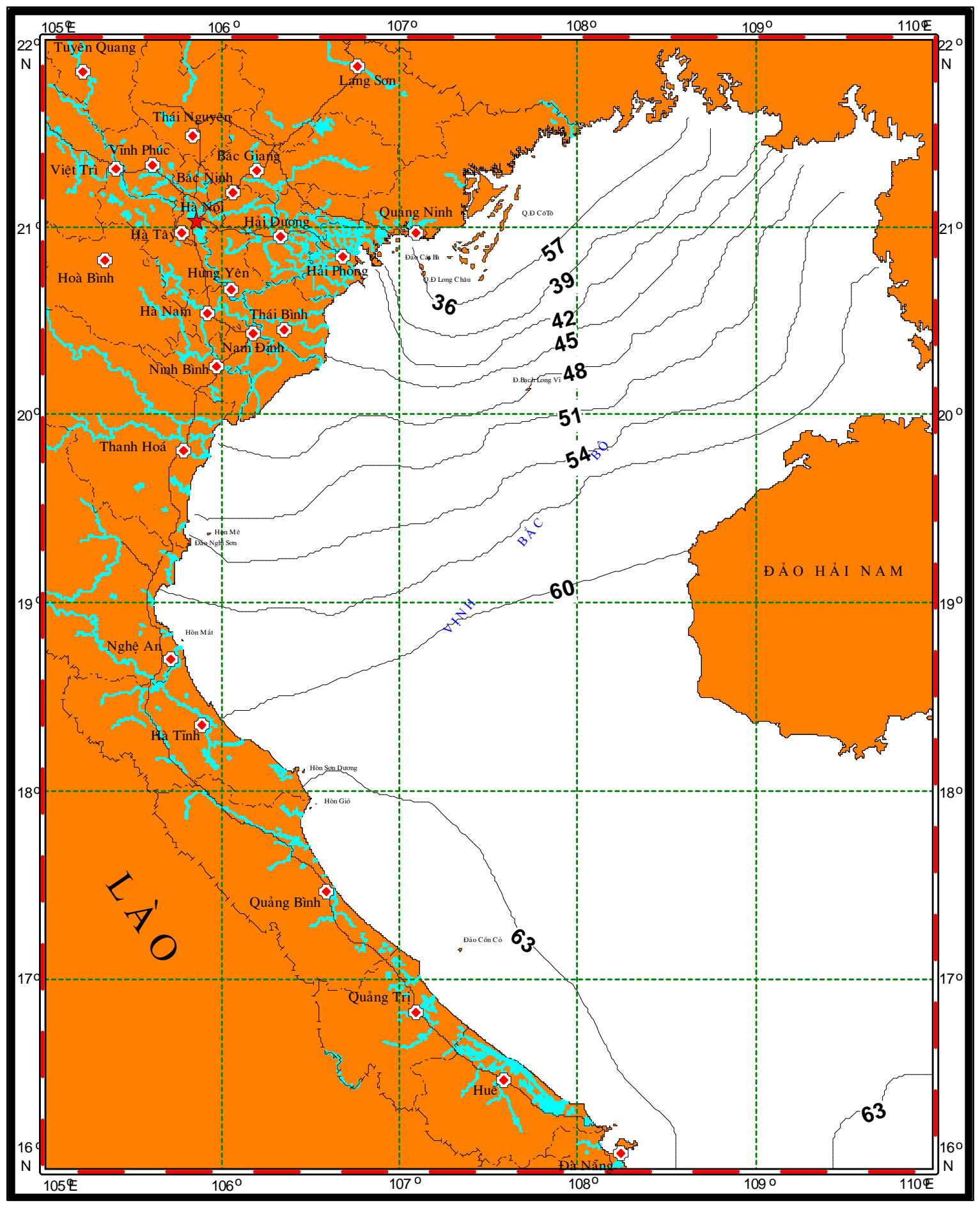

Hình 4: Giá trị trung bình năng suất thô $\left(\mathrm{mgC} / \mathrm{m}^{3} /\right.$ ngày) tháng 1 


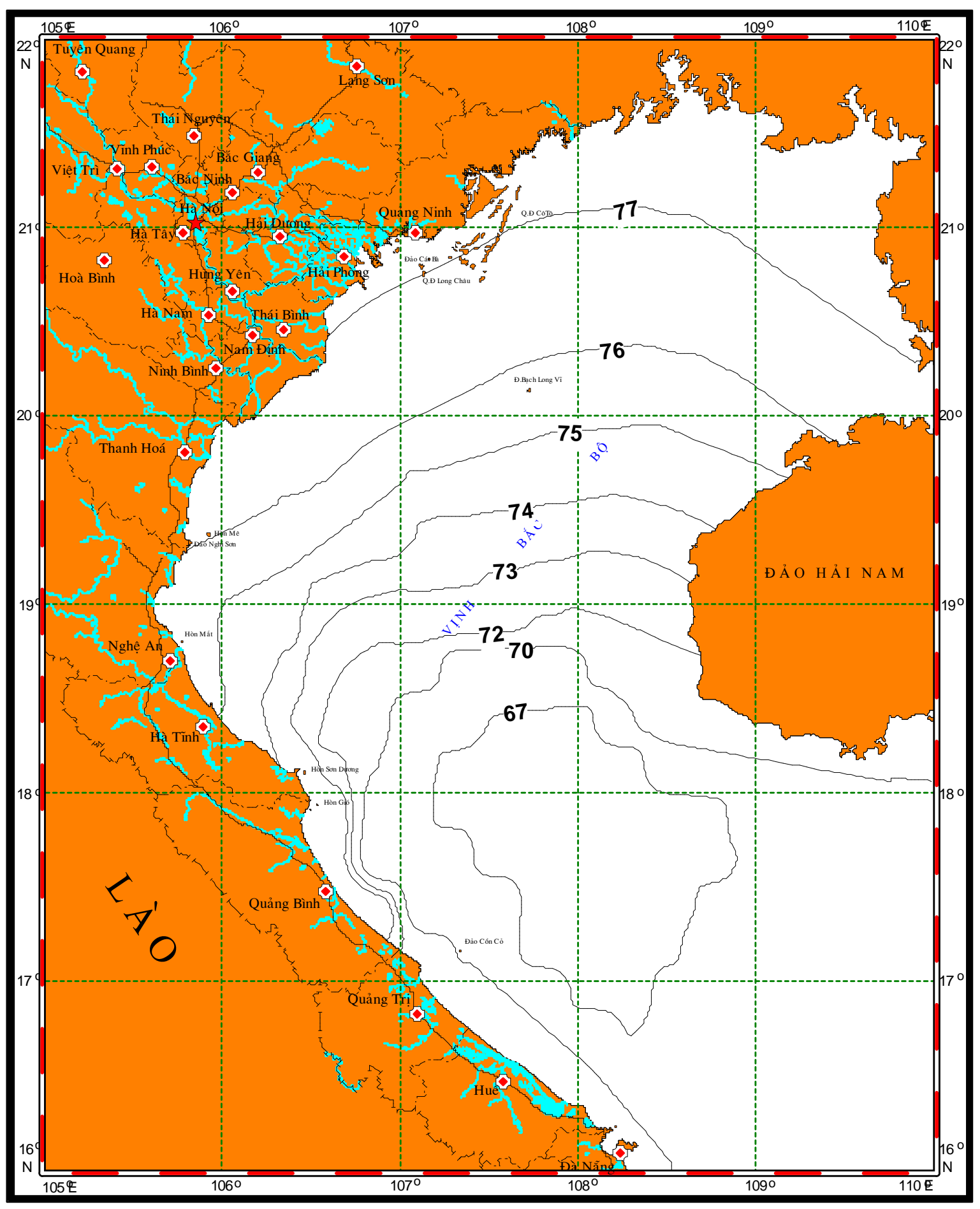

Hình 5: Giá trị trung bình năng suất thô $\left(\mathrm{mgC} / \mathrm{m}^{3} / \mathrm{ngày}\right)$ tháng 7 


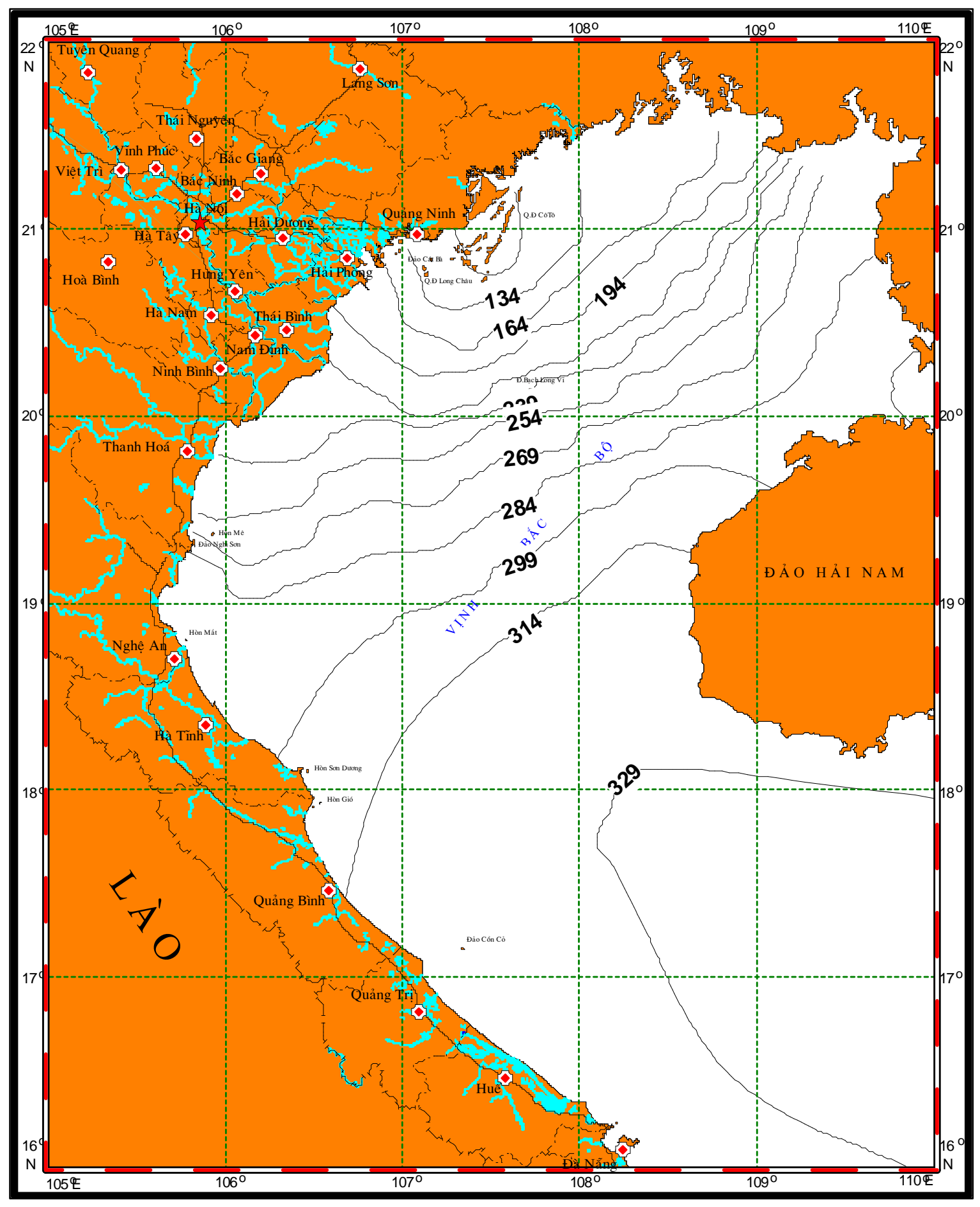

Hình 6: Giá trị trung bình sinh khối động vật nổi $\left(\mathrm{mg}\right.$-tươi $\left./ \mathrm{m}^{3}\right)$ tháng 1 


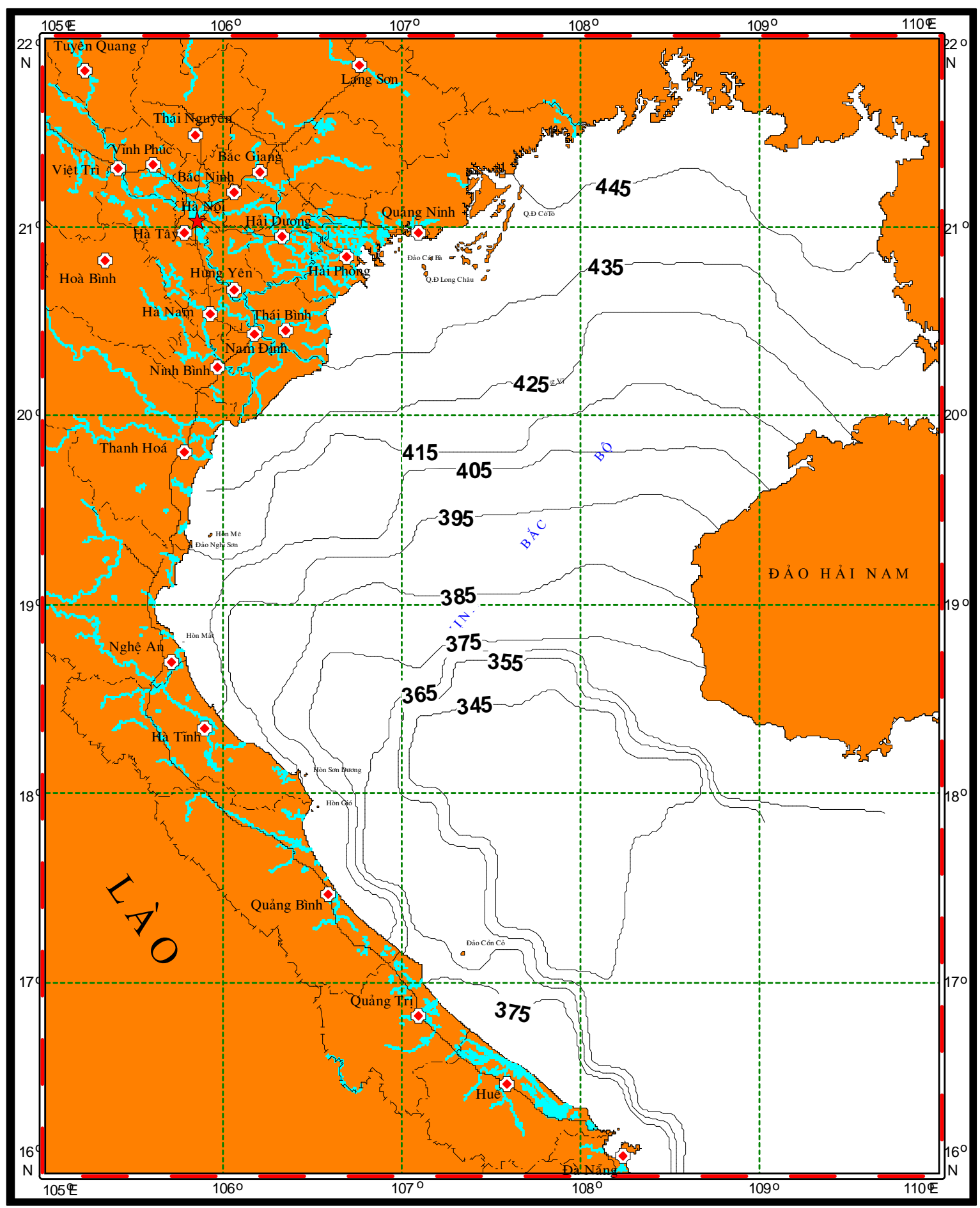

Hình 7: Giá trị trung bình sinh khối động vật nổi $\left(m g-t u ̛ o ̛ i / m^{3}\right)$ tháng 1 


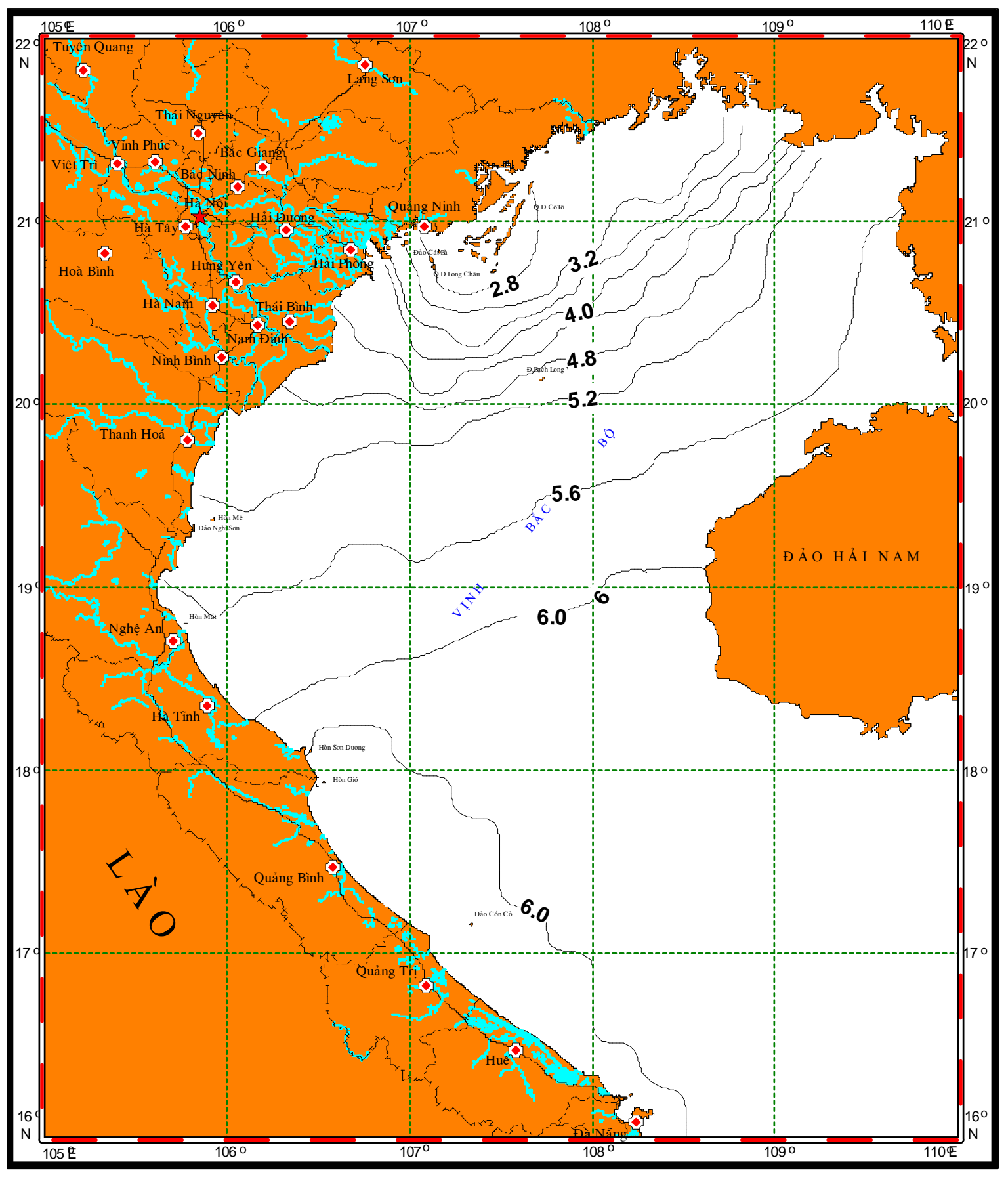

Hình 8: Giá trị trung bình năng suất thứ cấp $\left(\mathrm{mgC} / \mathrm{m}^{3} /\right.$ ngày) tháng 1 


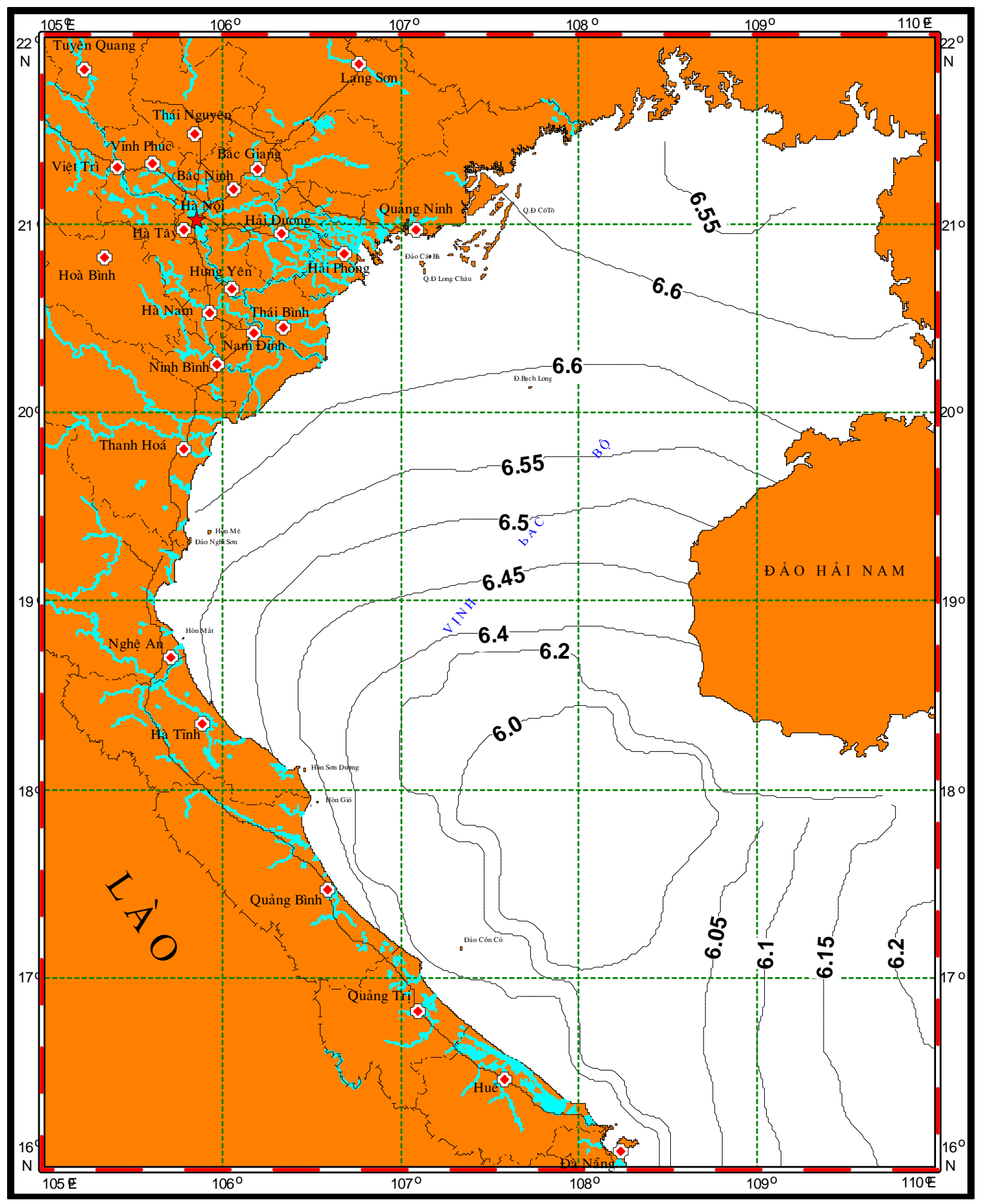

Hình 9: Giá trị trung bình năng suất thứ cấp $\left(\mathrm{mgC} / \mathrm{m}^{3} /\right.$ ngày) tháng 7 


\section{KẾT LUẬN VÀ KHUYẾN NGH!̣}

Mùa đông do nhiệt độ nước giảm thấp với dải nhiệt tương đối rộng $\left(19-23^{\circ} \mathrm{C}\right)$, cường độ bức xạ không lớn, lượng dinh dưỡng từ sông tải ra vịnh cũng không nhiều tạo ra bất lợi cho sự phát triển của thực vật nổi. Sinh khối của thực vật nổi ở khu vực này đạt khoảng $1110-1120 \mathrm{mg}$-tươi $/ \mathrm{m}^{3}$ trung bình $1103 \mathrm{mg}$-tươi $/ \mathrm{m}^{3}$. Đây là thời kỳ có sinh khối thực vật nổi thấp nhất trong năm. Điều này một lần nữa thể hiện sự hạn chế quá trình hô hấp tiêu hao vật chất do nền nhiệt giảm thấp, hiệu suất chuyển hoá năng lượng tự nhiên không cao, một phần do cường độ bức xạ tự nhiên trong các tháng mùa đông giảm, song phần chủ yếu do quá trình tổng hợp chất hữu cơ của thực vật nổi nhỏ.

Mùa hè là mùa phát triển của thực vật nổi với sinh khối hầu khắp vịnh đạt trong khoảng 1132 - 1197 mg-tươi $/ \mathrm{m}^{3}$, giá trị trung bình lớn nhất đặt 1159,77 mg-tươi $/ \mathrm{m}^{3}$. Thời kỳ này nhiệt độ nước tầng mặt tăng cao trên $29^{\circ} \mathrm{C}$ và tương đối đồng nhất, lượng dinh dưỡng bổ sung từ lục địa dồi dào. Đây là một trong những điều kiện sinh thái thuận cho quá trình tổng hợp chất hữu cơ của thực vật nổi khu vực ven bờ Tây vịnh Bắc bộ. Về các hiệu suất sinh thái trong mùa hè: Hệ số $\mathrm{P} / \mathrm{B}$ ngày của thực vật nổi có giá trị trung bình 1.02 cho thấy tốc độ tổng hợp chất hữu cơ của một đơn vị sinh khối thực vật nổi khá cao; Hệ số P/B ngày của động vật nổi có giá trị trung bình 0.22 ; hiệu suất tự dưỡng luôn luôn lớn hơn 1 trung bình 1,7 chứng tỏ vật chất tổng hợp được không những đủ chi dùng cho chính thực vật nổi mà còn được tích luỹ khá nhiều trong sản phẩm tinh để các bậc dinh dưỡng tiếp theo sử dụng. Hiệu suất chuyển hoá năng lượng tự nhiên trung bình $0,02 \%$ là ở mức cao so với một số vùng biển ven bờ Việt Nam.

Do số liệu quan trắc các yếu tố dinh dưỡng chưa được thực hiện đầy đủ và chi tiết, nên phương pháp mô hình mô phỏng chu trình nitơ là rất có giá trị, cung cấp về chuỗi quá trình nitơ chuyển hóa trong hệ sinh thái biển. Có thể ứng dụng mô hình nghiên cứu này cho các vùng biển khác tại Việt Nam.

\section{TÀI LIỆU THAM KHẢO}

1. Nguyễn Tác An, 1977. Năng suất sinh học sơ cấp và hiệu ứng sinh thái của dòng nước trồi ở vùng biển Nam Trung bộ, Các công trình nghiên cúu vùng nuớc trồi mạh Nam Trung bộ, NXB. KH \& KT Hà Nội, tr. 114-130. 
2. Đỗ Trọng Bình, 1997. Kết quả tính toán năng suất sinh học sơ cấp và hiệu quả sinh thái của thực vật nổi vào mùa khô (tháng 1-1997) tại vịnh Hạ Long, Tài nguyên và Môi trường Biển, NXB. KH \& KT Hà Nội, T.4, tr. 206-213.

3. Đoàn Bộ, Nguyễn Đức Cự, 1996. Nghiên cứu năng suất sinh học sơ cấp của thực vật nổi trong hệ sinh thái vùng triều cửa sông Hồng, Tài nguyên và Môi truờng biển, NXB. KH \& KT Hà Nội, T.3, 1996, tr.169-176.

4. Đoàn Bộ, 1997. Mô hình toán học phân bố sinh vật nổi và năng suất sinh học sơ cấp ở vùng nước trồi thềm lục địa Nam Trung bộ, Tạp chí Sinh học, T.19, No 4, tr. 35-42.

5. Đoàn Bộ, 1998. Nghiên cứu năng suất sinh học quần xã Plankton vùng đầm phá Tam Giang-Cầu Hai bằng phương pháp mô hình toán, Tạp chí khoa hoc ĐHQGHN: Tuyển tập các công trình khoa học Hội nghị Khoa học ĐHKHTN: Ngành Khí tượng - Thuỷ văn - Hải duong, tr. 1-7.

6. Đinh Văn U’u, Đoàn Văn Bộ và nnk, 2000. Nghiên cưu cấu trúc 3 chiều (3D) thuỷ nhiệt động lực học biển Đông và ứng dụng của chúng, Báo cáo tổng kết đề tài $\mathrm{NCKH}$ cấp nhà nước KHCN-06-02, tài liệu lưu trữ tại Chương trình Biển KHCN06, Hà Nội 2000.

7. Doan Bo. Using the mathematical models to study the marine ecosystem of Binh Thuan-Ninh Thuan sea Area and Tam Giang-Cau Hai lagoon.

\title{
A MODEL ON NITROGEN TRANSFORMATION CYCLE IN MARINE ECOSYSTEM APPLIED IN GULF OF TONKIN
}

\author{
NGUYEN NGOC TIEN, NGUYEN CHI CONG, DU VAN TOAN
}

Summary: This paper presents the model on Nitrogen transformation cycle in the marine ecosystem has been established and used to study on primary productivity in Gulf of Tonkin. In the cycle, the Nitrogen element is transformated through 5 compounds: Phytoplankton, Zooplankton, Dissolved Organic Matter, Amonium and Nitrate. The transformation processes in the cycle ware simulated by system of 5 differential equations.

Some results from application of the model to Gulf of TonKin shows that: The rough primary productivity in the gulf in winter is about 30 to $63 \mathrm{mgCl} / \mathrm{m}^{3} /$ day, average 57 $\mathrm{mgC} / \mathrm{m}^{3} /$ day and pure primary productivity is about 5 to $25 \mathrm{mgCl} \mathrm{m}^{3} /$ day, average 21 $m g C / \mathrm{m}^{3} /$ day. Average of $P / B$ day coefficient of phytoplankton is 0.85 , the autotroph productivity is 1.54, of natural energy transformation coefficient is $0.03 \%$. In summer, the rough primary productivity is about 67 to $77 \mathrm{mgCl} \mathrm{m}^{3} /$ day, average $72,43 \mathrm{mgCl} \mathrm{m}^{3} /$ day, pure 
primary productivity is about 28 to $32 \mathrm{mgC} / \mathrm{m}^{3} /$ day, average $30 \mathrm{mgC} / \mathrm{m}^{3} /$ day, the secondary productivity is about 6.0 to $6.6 \mathrm{mgC/ \textrm {m } ^ { 3 }} /$ day, average $6.36 \mathrm{mgCl} \mathrm{m}^{3} /$ day. Average of $P / B$ day coefficient of phytoplankton is 1.02, the autotroph productivity is 1.7 , natural energy transformation coefficient is $0.02 \%$.

Ngày nhận bài: 25 - 01 - 2011

Nguoòi nhận xét: PGS. TS. Nguyễn Chu Hồi 